\title{
Should Aerosolized Antibiotics Be Used to Treat Ventilator-Associated Pneumonia?
}

\author{
Changsheng Zhang MD, Lorenzo Berra MD, and Michael Klompas MD \\ Introduction \\ Rationale of Administrating Antibiotics via Inhalation \\ History of Inhaled Antibiotics \\ Purpose of This Review \\ Pro: Aerosolized Antibiotics Should Be Used to Treat Ventilator- \\ Associated Pneumonia \\ Specific Requirements Related to Antibiotic Nebulization \\ Delivery Systems \\ Lessons From Animal Studies \\ Lessons From Clinical Trials \\ Con: Aerosolized Antibiotics Should NOT Be Used to Treat Ventilator- \\ Associated Pneumonia \\ Summary
}

\begin{abstract}
In patients with ventilator-associated pneumonia, systemic use of antibiotics is the cornerstone of medical management. Supplemental use of aerosolized antibiotics with intravenous antibiotics in both experimental and clinical studies has been shown to have the following pharmacologic benefits: (1) aerosolized antibiotics reach the infected lung parenchyma without crossing the pulmonary alveolar capillary barrier; (2) aerosolized antibiotics increase anti-bacterial efficacy through increased local antibiotic concentration; and (3) aerosolized antibiotics decrease systemic toxicity. These benefits may be particularly beneficial to treat pneumonia caused by multidrug-resistant pathogens. Clinical data on the benefits of aerosolized antibiotics are more limited. Studies to date have not clearly shown improvements in time to extubation, mortality, or other patient-centered outcomes. At present, amikacin, colistin, and ceftazidime are the most frequently used and studied aerosolized antibiotics. This review summarizes the characteristics of aerosolized antibiotics, reviews the advantages and disadvantages of using aerosolized antibiotics, and calls for future investigations based on animal study data. Key words: ventilator-associated pneumonia; aerosol; antibiotics; delivery device; mechanical ventilation. [Respir Care 2016;61(6):737-748. @ 2016 Daedalus Enterprises]
\end{abstract}

\section{Introduction}

Ventilator-associated pneumonia (VAP) remains an important infectious complication of intensive care and me-

Drs Zhang and Berra are affiliated with the Department of Anesthesia, Critical Care and Pain Medicine, Massachusetts General Hospital, Boston, Massachusetts. Dr Klompas is affiliated with the Department of Population Medicine, Harvard Medical School and Harvard Pilgrim Health Care Institute, and the Department of Medicine, Brigham and Women's Hospital, Boston, Massachusetts. chanical ventilation, commonly due to multidrug-resistant pathogens such as Pseudomonas aeruginosa and Staphylococcus aureus ${ }^{1}$. It is also a major cause of hospital morbidity, mortality, and high health-care costs despite diag-
Drs Berra and Klompas presented a version of this paper at the 54th
RESPIRATORY CARE Journal Conference, "Respiratory Care Contro-
versies III," held June 5-6, 2015, in St Petersburg, Florida.

The authors have disclosed no conflicts of interest 
nostic and therapeutic improvements. ${ }^{2-4}$ At present, the general approach to VAP is early diagnosis and early initiation of broad-spectrum intravenous antibiotics, followed by antibiotic de-escalation based on available microbiological results. ${ }^{5}$ The ability of intravenous antibiotics, including $\beta$-lactams, aminoglycosides, and vancomycin, to cross into the lung parenchyma is markedly inhibited by both host-related factors (eg, mechanical injury) and physical and chemical drug-related factors (eg, drug mass, electrical charge, and lipophilic properties).6,7 Antibiotic concentrations in the lung are as low as $50 \%$ of the plasma concentrations for antibiotics such as colistin, amoxicillin, cefdinir, and meropenem, because the alveolar-capillary membrane has a high resistance to intravenous antibiotics. ${ }^{8,9}$ Inadequate concentrations of such antibiotics may result in failure to reach minimal inhibitory concentration. Treatment failure may extend the need for oral or intravenous antibiotic therapy and increase the required dosage. As a result, microbial drug resistance and systematic toxicity emerge. ${ }^{10}$

Aerosolized antibiotics are a promising approach to optimize drug delivery, although the addition of aerosolized antibiotics is recommended only for difficult-to-treat bacteria in cases where systemic antibiotics are not effective. ${ }^{11}$ Aerosolized medication has been successfully implemented in the treatment of obstructive lung disease. The delivery of drugs via the airways were first extensively studied in the case of bronchodilators. ${ }^{12,13}$ Treatment with inhaled $\beta_{2}$ agonists and steroids has rapid and effective onset and decreases the frequency and severity of adverse systemic effects. Aerosolized antibiotics in the treatment of pneumonia have not been thoroughly studied. In this review, we will present the relevant literature and our interpretation of different clinical implementations of aerosolized antibiotics.

\section{Rationale of Administrating Antibiotics via Inhalation}

An effective antibiotic treatment should fulfill the following three requirements: (1) the antimicrobial agent should quickly reach the infected location; (2) it must bind to a target site; and (3) it should execute its antimicrobial properties with no adverse effects ${ }^{14,15}$. Although intravenous infusion and oral administration are the most common routes of antibiotic delivery, they rarely fulfill these three characteristics. The advantages of using aerosolized antibiotics compared with oral administration or intravenous infusion can be summarized as follows: The antibi-

Correspondence: Lorenzo Berra MD, Department of Anesthesia, Critical Care and Pain Medicine, Massachusetts General Hospital, White 434B, 55 Fruit Street, Boston, MA 02114. E-mail: lberra@partners.org.

DOI: $10.4187 /$ respcare. 04748 otics can directly reach the infected alveolar space; therefore, the antibiotics are better able to decrease bacterial concentration, inflammation, and lung damage. ${ }^{16}$ Depending on aerosol particle size (usually between 1 and $5 \mu \mathrm{m}$ ) and flow turbulences, differing amounts of antibiotics can deposit to distal bronchioles and alveolar spaces. ${ }^{17,18}$ Additionally, the slow diffusion of localized antibiotics through the alveolar-capillary barrier keeps the antibiotic concentration high at the infection site. Early in the 1970s, studies demonstrated a positive correlation between a more rapid clinical response to treatment of a bacterial bronchopulmonary infection and the local concentration (eg, sputum concentration) of an antibiotic in relation to the antibiotic's minimal inhibitory concentration. ${ }^{19-21}$ Thus, increased lung tissue concentration of antibiotics may provide better and longer lasting control of parenchymal infection and tracheobronchial colonization. Finally, high local antibiotic concentrations could decrease the necessary dose and duration of intravenous antibiotic infusion, which could prevent antibiotic resistance and reduce antibiotic levels in the serum, decreasing systematic toxicity. ${ }^{22}$

\section{History of Inhaled Antibiotics}

The first reports on the use of nebulized antibiotics date back to the 1930s. ${ }^{13}$ In the 1940s, Segal et al ${ }^{23}$ were among the first to deliver antibiotics by inhalation to treat chronic airway infections. The history of inhaled antibiotic delivery is largely based on antibiotics used in cystic fibrosis. ${ }^{15}$ At that time, the fact that no reliable nebulizer was available hampered the development of inhaled antibiotic administration. Since then, many animal ${ }^{24-30}$ and clinical ${ }^{31-41}$ studies have investigated both the pharmacodynamics and pharmacokinetics of different categories of antibiotics and compared the bactericidal effect of aerosolized antibiotics with that of intravenous antibiotics. Notably, however, the FDA only cleared the use of inhaled tobramycin for cystic fibrosis in 1997. Approval was delayed due to concerns regarding poor tolerance and significant bronchial irritation secondary to the hyperosmolarity of inhaled solutions and preservatives. ${ }^{42}$

\section{Purpose of This Review}

Despite the progress of the past decades, there are still several controversies regarding the timing of administration of aerosolized antibiotics, the selection of a patient population, and the delivery methods used with aerosolized antibiotics. As a result, there exists no routine use of aerosolized antibiotic treatment for respiratory tract infections. The purpose of this pro and con review is to summarize current literature, identify limitations and concerns of using aerosolized antibiotics in the treatment of VAP, and to suggest clinical applications and future research directions. 


\section{Pro: Aerosolized Antibiotics Should Be Used to Treat Ventilator-Associated Pneumonia}

The use of aerosolized antibiotics in the treatment of lung infection has been proven to have many potential advantages, including generation of high antibiotic concentrations at the site of infection and a reduction in systemic toxicity due to lower systemic antibiotic concentration.

\section{Specific Requirements Related to Antibiotic Nebulization}

Whether aerosolized antibiotics can be delivered to the lower airways and the efficacy of aerosolized antibiotics depends upon 4 factors. (1) The size of the aerosol particle should be kept between 1 and $3 \mu \mathrm{m} .{ }^{43}$ Byron $^{44}$ reported that $90 \%$ of inhaled aerosol particles with an aerodynamic diameter of 1-2 $\mu \mathrm{m}$, if slowly and deeply inhaled, can be deposited in the lungs and that a $1-\mu \mathrm{m}$ droplet is more likely to be deposited in the most distal parts of the lungs as opposed to the proximal parts. ${ }^{44,45}$ Particles of $>5 \mu \mathrm{m}$ are unable to reach peripheral airways and are deposited in the main airways, whereas particles of $<0.5 \mu \mathrm{m}$ are too light and will exit the respiratory system along with expired gases. ${ }^{46}$ Small antibiotic particles of $<0.5 \mu \mathrm{m}$ could thus increase the rate of antimicrobial resistance due to a failure to achieve minimal inhibitory concentration. (2) Air flow should be laminar during inhalation of antibiotics, and asynchrony should be minimized to minimize extrapulmonary deposition on such places as respiratory ventilation tubing, the endotracheal tube, the expiratory filter, and the upper airways. ${ }^{47}$ Specific ventilator settings should be selected (eg, volume controlled mode with a long inspiratory time and an end-inspiratory pause) to avoid flow turbulence. ${ }^{48}$ (3) For mechanically ventilated patients, asynchrony should be avoided to guarantee drug delivery, which requires proper sedation. ${ }^{49}$ (4) Nebulized antibiotics must be stable and have relatively physiologic $\mathrm{pH}$ and should not provoke bronchoconstriction (cough and wheezing). ${ }^{46}$

\section{Delivery Systems}

The technical characteristics of the delivery system (ie, nebulizers) are of crucial importance to successful use of aerosolized drugs. Ideally, an aerosol delivery system should have the following properties. (1) The generation of the particle size should be maintained between 1 and $3 \mu \mathrm{m}$; (2) the biological properties of the antibiotic should not be altered by nebulization processes; (3) the inhalation system should optimize the delivery rate of antibiotics (only small amounts of antibiotics should be lost in the airways or in the environment); (4) the delivery system should have a large reservoir; (5) it should be user-friendly
Table 1. Advantages and Disadvantages of Major Delivery Systems

\begin{tabular}{|c|c|c|}
\hline Delivery systems & Advantages & Disadvantages \\
\hline \multirow[t]{5}{*}{ Jet nebulizer } & Easy to use & $\begin{array}{l}\text { Low drug delivery rate } \\
\qquad(15 \%)\end{array}$ \\
\hline & Low cost & $\begin{array}{l}\text { Heterogeneously sized } \\
\text { particles }\end{array}$ \\
\hline & & High gas flow requirement \\
\hline & & $\begin{array}{l}\text { Generation of turbulent } \\
\text { flow }\end{array}$ \\
\hline & & Difficult to clean \\
\hline \multirow[t]{4}{*}{ Ultrasonic nebulizer } & $\begin{array}{l}\text { Good drug delivery } \\
\text { rate }(30-40 \%)\end{array}$ & Increases drug temperature \\
\hline & $\begin{array}{l}\text { No need for driving } \\
\text { gas }\end{array}$ & Large residual volume \\
\hline & $\begin{array}{l}\text { Particle size ranging } \\
\text { from } 3.7 \text { to } 10.5 \\
\mu \mathrm{m}\end{array}$ & $\begin{array}{l}\text { Inability to aerosolize } \\
\text { viscous solutions }\end{array}$ \\
\hline & Silent & \\
\hline \multirow[t]{3}{*}{$\begin{array}{l}\text { Vibrating mesh } \\
\text { nebulizer }\end{array}$} & $\begin{array}{l}\text { Best drug delivery } \\
\text { rate }(40-60 \%)\end{array}$ & Pores can clog \\
\hline & $\begin{array}{l}\text { Size of drug particle } \\
\text { adjustable }\end{array}$ & Difficult to clean \\
\hline & $\begin{array}{l}\text { Low-velocity } \\
\text { aerosol }\end{array}$ & High cost \\
\hline
\end{tabular}

and easy to manipulate; and (6) patient comfort should be optimal.

At present, several kinds of aerosol delivery devices are commercially available for antibiotics, including smallvolume nebulizers $(\sim 6 \mathrm{~mL})$, pressurized metered-dose inhalers, and dry powder inhalers. ${ }^{50}$ The most common smallvolume nebulizers are the jet nebulizer, the vibrating mesh nebulizer, and the ultrasonic nebulizer. Jet nebulizers often create turbulent flow and have a low drug delivery rate (only 15\% of the aerosolized antibiotics are delivered to the lung parenchyma). ${ }^{51,52}$ Ultrasonic nebulizers have a better delivery rate $(30-40 \%)$ compared with jet nebulizers but increase the temperature of the antibiotic solution, which may affect the biological activity of the medications. ${ }^{53}$ Vibrating mesh nebulizers, which use a micropump technology for aerosol production, have the best efficacy of $40-60 \%$ and can minimize drug wasting by synchronizing delivery of the drug to inspiration. ${ }^{54}$ The particle size of inhaled antibiotics can be adjusted by changing the diameter of tapered holes on the plate. ${ }^{28}$ The advantages and disadvantages of most common commercially available delivery systems are summarized in Table 1 .

To deliver enough antibiotics to the lung, nebulizers need to work with a large reservoir. ${ }^{55}$ Thus, pressurized metered-dose inhalers, including conventional and breathactuated pressurized metered-dose inhalers, are preferred for the delivery of aerosolized antibiotics. However, large reservoirs with large amounts of antibiotics might be economically unfavorable when using expensive antibiotics, and a smaller sized reservoir might be cheaper. 
Additionally, before administration of inhaled antibiotics, clinicians should focus on optimization of the patient's overall respiratory status to obtain effective inhaled antibiotic treatment. We list here the most important interventions to pursue before drug treatment: (1) ensuring patient comfort and synchrony with the ventilator, ${ }^{37}$ (2) drainage or suction of secretions from the tracheobronchial tree, (3) lung recruitment, ${ }^{56,57}$ (4) use of a bronchodilator (albuterol) in cases of bronchospasm to optimize gas flow, (5) avoiding tube kinking and asynchrony, ${ }^{55}$ (6) synchronizing aerosol generation with the inspiratory phase, ${ }^{58}$ and (7) maintaining physiological temperature and humidification of inspiratory gas..$^{59,60}$

\section{Lessons From Animal Studies}

VAP animal models have been used to test the efficacy of combining systemic and aerosolized antibiotics in the treatment of experimental pneumonia and to examine the pharmacodynamics of nebulized antibiotics. We summarize the relevant animal studies in Table 2.

In 2002, Goldstein et al ${ }^{25}$ performed a pharmacodynamics study in piglets comparing intravenous infusion of amikacin with aerosolized amikacin. They found that lung concentrations of amikacin when inhaled are 10 times greater than with intravenous administration; amikacin was homogeneously distributed throughout the lung parenchyma in both intravenous and aerosol delivery groups; and amikacin concentrations were always above the minimal inhibitory concentrations of most Gram-negative strains in the aerosolized group, despite only $38 \%$ of the delivered initial dose reaching the lung parenchyma. The concentration of aerosolized amikacin in the lungs remains higher than the concentration achieved intravenously even in cases of pulmonary consolidation due to bronchopneumonia, as described by Goldstein et al. ${ }^{61}$

In the study published by $\mathrm{Lu}$ et $\mathrm{al},{ }^{29}$ the authors used nebulized and intravenous colistin in ventilated piglets with induced $P$. aeruginosa pneumonia. Colistin was undetectable in the lung tissue following the intravenous infusion. The bacterial counts were $<10^{2}$ colony-forming units/g after $24 \mathrm{~h}$ of treatment in $67 \%$ of pulmonary segments following colistin nebulization versus $28 \%$ of pulmonary segments following intravenous administration. Nebulized colistin was shown to rapidly alleviate pneumonia symptoms and execute bactericidal effects.

\section{Lessons From Clinical Trials}

Clinical investigators have tested the efficacy of aerosolized antibiotics in the treatment of pneumonia in only a few clinical trials. The major indicators for the effectiveness of aerosolized antibiotic treatment were the clinical response rate, which includes complete or partial resolu- tion of the signs and symptoms of infection, and the microbiological eradiation rate. ${ }^{62}$

In a randomized control trial performed by Palmer et al, ${ }^{48}$ the authors hypothesized that supplemental aerosolized antibiotics could effectively treat respiratory infection and decrease the length of systemic antibiotic use. After comparing the clinical outcomes (ie, VAP rate and clinical pulmonary infection score) between aerosolized antibiotics and aerosolized saline placebo, they found that the aerosolized antibiotic group had reduced signs and symptoms of respiratory infection and that the incidence of VAP decreased from 73.6 to $35.7 \%$ in critically ill subjects. The inhaled antibiotics facilitated weaning $(84.2 \%$ in the aerosol antibiotic group vs $54.1 \%$ in the control group) and reduced bacterial resistance ( 0 in the aerosol antibiotic group vs $33.3 \%$ in the control group) and the length of use of systemic antibiotics.

In another clinical trial testing the ability of inhaled antibiotics to reduce bacterial resistance, ${ }^{41}$ researchers found that aerosolized antibiotics could eradicate 26 of 27 organisms present at the time of study randomization compared with 2 of 23 organisms with placebo. In addition, resistance to systemic antibiotics significantly decreased with the use of aerosolized antibiotics. Furthermore, aerosolized antibiotics have been demonstrated in clinical trials to be efficacious because higher local concentrations were delivered with low systemic exposure. ${ }^{63,64}$ The concentration of the inhaled drug in the lung has been found to be as high as 100 times the systemic concentration. ${ }^{63}$ Related clinical trials are summarized in Table 3. Future studies should be carried out to investigate the optimal methods of delivering antibiotics, the optimal respiratory management of patients during drug nebulization (eg, recruitment of lung parenchyma before drug administration), and the pharmacodynamics of nebulized antibiotics in critically ill patients.

In summary, aerosolized antibiotics have been shown to be potent bactericidal agents through their ability to create increased drug concentrations in the lung. The use of aerosolized antibiotics reduces systemic toxicity by reducing plasma drug levels, especially in the case of colistin. Finding ways to improve delivery systems and optimize patient respiratory status is of crucial importance in any future clinical studies investigating the effects of aerosolized antibiotics on outcomes.

\section{Con: Aerosolized Antibiotics Should NOT Be Used to Treat Ventilator-Associated Pneumonia}

At first blush, the merits of aerosolized antibiotics to treat ventilator-associated pneumonia appear obvious and overwhelming. Aerosolization in theory optimizes drug delivery to the pulmonary parenchyma by bypassing the poor lung penetration of many antibiotics. Aerosolization 


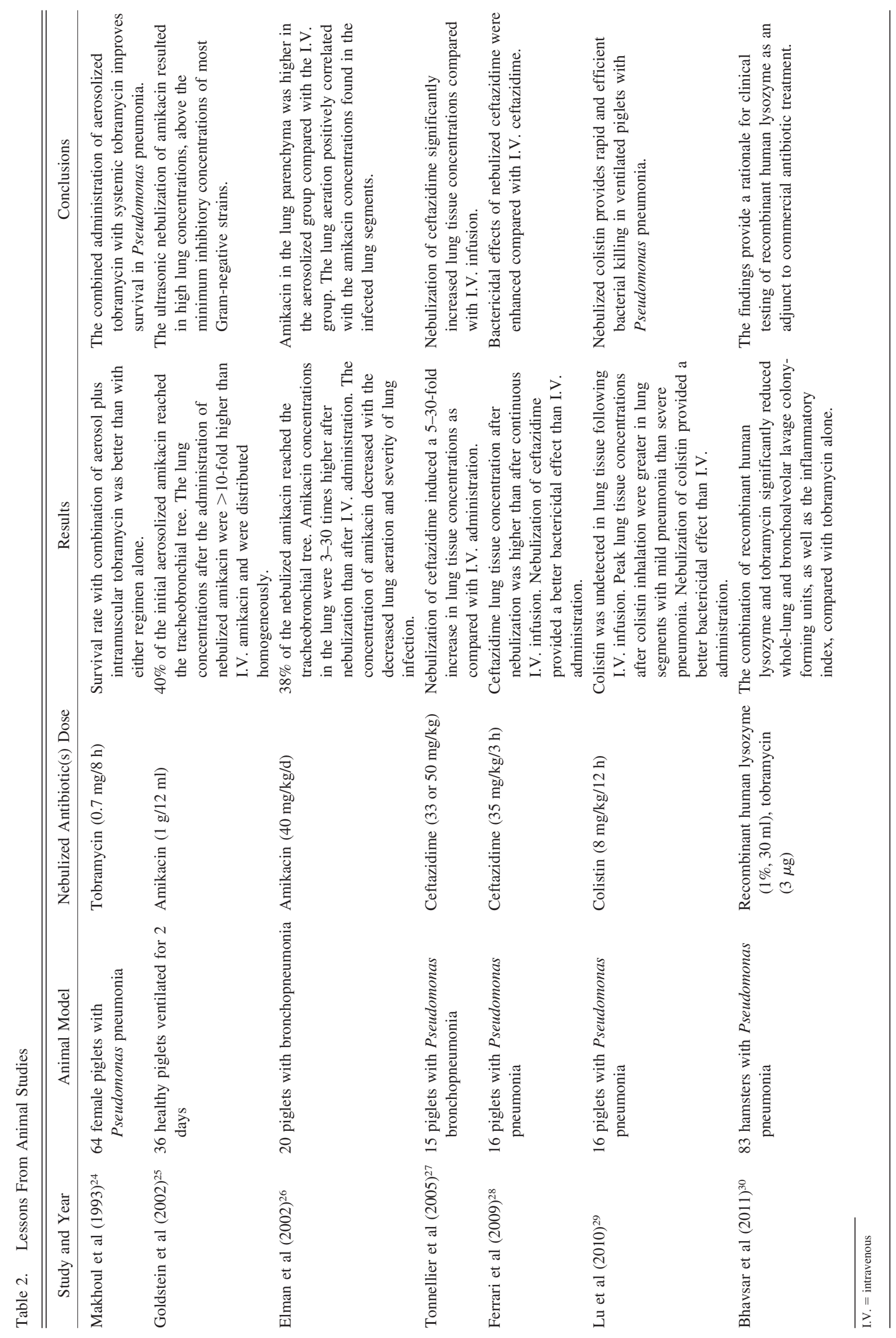




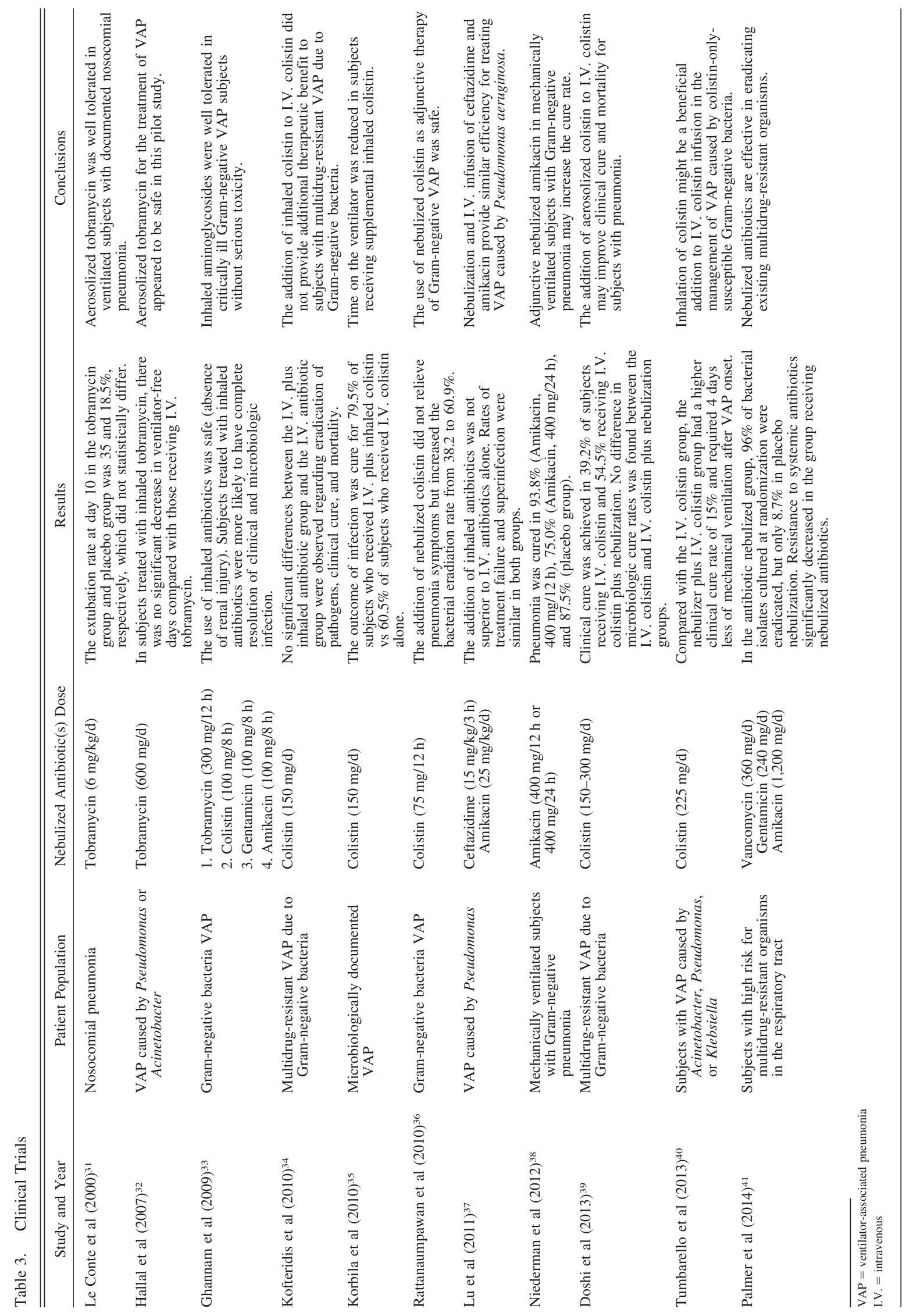


therefore makes it possible to achieve high local concentrations of antibiotic relative to organisms' minimum inhibitory concentrations while simultaneously minimizing systemic toxicities by concentrating antibiotics in the lungs rather than spreading them throughout the body. These potential benefits are particularly attractive to treat VAP due to multidrug-resistant pathogens, where there may be few therapeutic options, and those few options have particularly poor pulmonary penetration when given intravenously (ie, polymixins and aminoglycosides). ${ }^{29,65}$ The limited data on hand, however, paint a more nuanced picture of aerosolized antibiotics' potential. Many of the proposed advantages of aerosolized antibiotics have significant caveats, there are significant practical challenges to delivering aerosols effectively, and the small amount of controlled trial data we have on hand thus far do not yet show that adjunctive aerosols improve patient-centered outcomes.

Each of the potential advantages of aerosolizing antibiotics has important nuances. It is possible to achieve high tracheal concentrations of antibiotics with aerosols, but this may be of limited benefit when treating dense consolidations where the majority of infection is "protected" behind plugs of mucus and pus that obstruct the pathway between the trachea and parenchyma. Indeed, even small amounts of purulent secretions in the proximal airways can inhibit parenchymal drug delivery by creating local turbulence, disrupting laminar air flow, and forcing aerosol deposition in the proximal airways rather than in the deep parenchyma. Experimental studies of inoculation pneumonia in piglets document an inverse relationship between lung aeration and parenchymal antibiotic concentrations. ${ }^{26}$

The notion that aerosolization limits systemic absorption is also questionable. Healthy lungs absorb very little antibiotics from aerosols, but infected and inflamed lungs absorb far more. In practice, it is possible to achieve similar serum concentrations of antibiotics in patients with dense pneumonias regardless of whether the drugs are given intravenously or via the airways. ${ }^{28,61}$ Paradoxically then, this means that treating patients with both intravenous and aerosolized antibiotics could theoretically potentiate risk for adverse drug events by effectively doubling drug delivery to the serum. Some investigators therefore suggest using aerosolized antibiotics as a replacement for rather than as an adjunct to intravenous antibiotics. This strategy also has risk, however, because it may lead to undertreatment of patients with bacteremia or a second locus of infection outside the lungs. Notwithstanding the enhanced absorption capacity of inflamed lungs, it is not clear that aerosols can consistently and reliably achieve serum levels of antibiotics equivalent to intravenous doses throughout the course of therapy. Investigators advise against using aerosolized antibiotics alone until bacteremia is excluded.
There are many practical challenges to delivering aerosolized antibiotics effectively. Failure to appreciate the mechanics of aerosolization and the techniques required to achieve optimal drug delivery may lead to loss of the majority of antibiotic to the ventilator circuit and endotracheal tube. At the same time, optimizing drug delivery may require non-physiological ventilator settings and/or enhanced sedation that may paradoxically introduce harms of their own.

Multiple factors affect the likelihood of effective antibiotic delivery, including aerosol particle size, method of aerosolization, temperature and humidity of the carrying gas, ventilator settings, patient-ventilator synchrony, and severity of pneumonia. ${ }^{55}$ Jet nebulizers, for example, create highly turbulent flow that can lead to $>85 \%$ of the antibiotic dose depositing in the ventilator circuit and endotracheal tube rather than in the lungs. ${ }^{66}$ Ultrasonic nebulizers are more likely to achieve laminar flow, but they can increase the temperature of the antibiotic solution and thereby alter its chemical properties. Heat and humidification increase the diameter of aerosol particles, which then increases drug deposition in the respiratory circuit and proximal airways rather than in deep lung tissue. Very specific ventilator settings are required to achieve laminar flow. Rouby et al, ${ }^{55}$ for example, recommend using volume control with constant inspiratory flow, a minute ventilation of $<6 \mathrm{~L} / \mathrm{min}$, a breathing frequency of 12 breaths/min, an inspiratory-expiratory ratio of $<50 \%$, and an end-inspiratory pause of $<20 \%$. These settings may be uncomfortable for some patients, and/or they may fail to meet patients' physiologic requirements. This in turn may require deeper sedation or, in extreme cases, neuromuscular blockade, which in turn are both associated with potential risks of their own. Some investigators have also documented the potential for aerosolization to cause unintended harms, including a reported case of cardiac arrest secondary to obstruction of the expiratory filter. ${ }^{37}$

Ultimately, we need to evaluate the available clinical trial data to evaluate whether on balance aerosolization is helpful, harmful, or neutral for patients. Interpreting the available trial data, however, requires some caution. The primary outcomes in most published studies are clinical cure and microbiological cure. These are both problematic. The diagnosis of VAP is notoriously subjective, inaccurate, and subject to bias. ${ }^{67,68}$ This is a particular risk in open label studies, where investigators may subconsciously interpret subjective clinical criteria more strictly in one arm of the study versus the other and therefore bias the study in favor of the intervention arm. ${ }^{69}$ Microbiologic cultures are equally problematic. The oropharynx and endotracheal tubes of ventilated patients are invariably colonized with bacteria. Positive cultures alone correlate poorly with histologically confirmed pneumonia. ${ }^{70}$ Conversely, aerosolized antibiotics may effectively sterilize 
the upper airway and endotracheal tube, but this does not necessarily mean that they have eradicated deep parenchymal pneumonias. Given these risks of bias, it is very important to consider more objective outcomes, such as duration of mechanical ventilation or mortality rates, to evaluate the true impact of aerosolized antibiotics.

A study by Lu et al ${ }^{37}$ provides a telling example of the potential mismatch between clinical or microbiological improvements and more objective outcomes. Lu et al ${ }^{37}$ randomized 46 subjects with VAP to treatment with aerosolized versus intravenous antibiotics. They reported trends toward higher clinical success rates $(70 \%$ vs $55 \%)$ and higher microbiological cure rates ( $85 \%$ vs $70 \%$ ) with aerosolized antibiotics but opposite trends for duration of mechanical ventilation (median $29 \mathrm{~d}$ for aerosolized antibiotics vs $18 \mathrm{~d}$ with intravenous), ICU stay ( $24 \mathrm{~d}$ vs $16 \mathrm{~d}$ ), and mortality (10\% vs 5\%). The small number of subjects in this study precluded any definitive conclusions, but the differential trend directions in clinical and microbiological cure versus duration of mechanical ventilation and mortality bespeak the importance of focusing on the latter, more objective and patient-centered outcomes.

A recent meta-analysis provides a convenient summary of studies published to date comparing clinical impacts with intravenous therapy alone versus intravenous therapy along with adjunctive aerosolized antibiotics. ${ }^{71}$ The metaanalysis included 12 controlled studies: 6 observational and 6 randomized controlled trials. The analysis found that adjunctive aerosolized antibiotics were associated with higher clinical cure rates (risk ratio [RR] 1.23, 95\% CI 1.05-1.43) and a nonsignificant trend toward higher microbiological cure rates (RR 1.24, 95\% CI 0.92-1.55). There were no differences between arms, however, in the incidence of nephrotoxicity (RR 1.05, 95\% CI 0.70-1.57), mean duration of mechanical ventilation (standardized mean difference $-0.10 \mathrm{~d}, 95 \% \mathrm{CI}-1.22$ to 1.00 ), ICU stay $(0.14 \mathrm{~d}, 95 \% \mathrm{CI}-0.46$ to 0.73 ), or mortality (RR $0.90,95 \%$ CI $0.76-1.08$ ).

Furthermore, there were important caveats regarding the signal, suggesting higher clinical cure rates with adjunctive aerosolized antibiotics. The signal was driven entirely by observational studies (RR 1.33, 95\% CI 1.09-1.62). When the investigators restricted the analysis to randomized controlled trials alone, there was no longer any significant difference in clinical cure rates (RR 1.05, 95\% CI $0.88-1.26)$. Likewise, the apparent trend toward lower mortality rates in subjects treated with adjunctive aerosolized antibiotics (RR 0.90, 95\% CI 0.76-1.08) was also driven by the observational studies (RR 0.86, 95\% CI 0.70-1.04). The trend went in the opposite direction when restricting the meta-analysis to randomized controlled trials alone (RR 1.11, 95\% CI 0.75-1.66).

To summarize then, the literature available to date does not yet demonstrate a clear clinical benefit to aerosolized antibiotics. Their use is complicated and carries some risk of harm to patients. It is important to note, however, that our knowledge of the clinical impact of aerosolized antibiotics is severely constrained by the small number of clinical trials published to date and the limitations of those trials that have been published (all were small, and only a fraction were randomized controlled trials). The theoretical benefits of aerosolized antibiotics still allow for the possibility that future studies will demonstrate some benefits, but the data in hand thus far do not support their widespread adoption for routine practice.

\section{Summary}

Treating VAP with aerosolized antibiotics combined with systemic antibiotics has bactericidal advantages compared with conventional treatment with intravenous antibiotics alone. To date, however, clinical trials are insufficient to support the broad use of inhaled antibiotics in critically ill patients with a diagnosis of VAP. Future studies should focus on improving delivery systems, patient selection, and patient respiratory optimization prior to drug nebulization.

\section{REFERENCES}

1. Barbier F, Andremont A, Wolff M, Bouadma L. Hospital-acquired pneumonia and ventilator-associated pneumonia: recent advances in epidemiology and management. Curr Opin Pulm Med 2013;19(3):216-228.

2. Chastre J, Fagon JY. Ventilator-associated pneumonia. Am J Respir Crit Care Med 2002;165(7):867-903.

3. Warren DK, Shukla SJ, Olsen MA, Kollef MH, Hollenbeak CS, Cox $\mathrm{MJ}$, et al. Outcome and attributable cost of ventilator-associated pneumonia among intensive care unit patients in a suburban medical center. Crit Care Med 2003;31(5):1312-1317.

4. Bergmans DC, Bonten MJ, Gaillard CA, van Tiel FH, van der Geest $\mathrm{S}$, de Leeuw PW, Stobberingh EE. Indications for antibiotic use in ICU patients: a one-year prospective surveillance. J Antimicrob Chemother 1997;39(4):527-535.

5. Fagon JY, Chastre J, Rouby JJ. Is bronchoalveolar lavage with quantitative cultures a useful tool for diagnosing ventilator-associated pneumonia? Crit Care 2007;11(2):123.

6. Valcke Y, Pauwels R, Van der Straeten M. Pharmacokinetics of antibiotics in the lungs. Eur Respir J 1990;3(6):715-722.

7. Rottbøll LA, Friis C. Penetration of antimicrobials to pulmonary epithelial lining fluid and muscle and impact of drug physicochemical properties determined by microdialysis. J Pharmacol Toxicol Methods 2015;78:58-65.

8. Kiem S, Schentag JJ. Interpretation of antibiotic concentration ratios measured in epithelial lining fluid. Antimicrob Agents Chemother 2008;52(1):24-36.

9. Ratjen F, Rietschel E, Kasel D, Schwiertz R, Starke K, Beier H, et al. Pharmacokinetics of inhaled colistin in patients with cystic fibrosis. J Antimicrob Chemother 2006;57(2):306-311.

10. Neuhauser MM, Weinstein RA, Rydman R, Danziger LH, Karam G, Quinn JP. Antibiotic resistance among gram-negative bacilli in US intensive care units: implications for fluoroquinolone use. JAMA 2003;289(7):885-888.

11. American Thoracic Society, Infectious Diseases Society of America. Guidelines for the management of adults with hospital-acquired, 


\section{Aerosolized Antibiotics in VAP}

ventilator-associated, and healthcare-associated pneumonia. Am J Respir Crit Care Med 2005;171(4):388-416.

12. Spier R, Witebsky E, Paine JR. Aerosolized pancreatic dornase and antibiotics in pulmonary infections: use in patients with postoperative and nonoperative infections. Jama 1961;178:878-886.

13. Labiris NR, Newhouse MT. Drug delivery: pulmonary delivery. In Encyclopedia of Pharmaceutical Science and Technology, 4th Edition. Abingdon, UK: Taylor \& Francis; 2013.

14. Moore RH, Khan A, Dickey BF. Long-acting inhaled $\beta 2$-agonists in asthma therapy. Chest 1998;113(4):1095-1108.

15. Flume $P$, Klepser ME. The rationale for aerosolized antibiotics. Pharmacotherapy 2002;22(3 Pt 2):71S-79S.

16. Chalmers JD, Smith MP, McHugh BJ, Doherty C, Govan JR, Hill AT. Short- and long-term antibiotic treatment reduces airway and systemic inflammation in non-cystic fibrosis bronchiectasis. Am J Respir Crit Care Med 2012;186(7):657-665.

17. Brain JD, Valberg PA. Deposition of aerosol in the respiratory tract. Am Rev Respir Dis 1979;120(6):1325-1373.

18. Dolovich MA. Influence of inspiratory flow rate, particle size, and airway caliber on aerosolized drug delivery to the lung. Respir Care 2000;45(6):597-608.

19. Stewart SM, Anderson IM, Jones GR, Calder MA. Amoxycillin levels in sputum, serum, and saliva. Thorax 1974;29(1):110-114.

20. Ingold A. Sputum and serum levels of amoxycillin in chronic bronchial infections. Br J Dis Chest 1975;69:211-216.

21. Maesen FP, Beeuwkes H, Davies BI, Buytendijk HJ, Brombacher PJ, Wessman J. Bacampicillin in acute exacerbations of chronic bronchitis: a dose-range study. J Antimicrob Chemother 1976;2(3):279-285.

22. Roberts MC. Antibiotic toxicity, interactions and resistance development. Periodontol 2000 2002;28:280-297.

23. Segal MS, Levinson L, Miller D. Penicillin inhalation therapy in respiratory infections. J Am Med Assoc 1947;134(9):762-770.

24. Makhoul IR, Merzbach D, Lichtig C, Berant M. Antibiotic treatment of experimental Pseudomonas aeruginosa pneumonia in guinea pigs: comparison of aerosol and systemic administration. J Infect Dis 1993; 168(5):1296-1299.

25. Goldstein I, Wallet F, Robert J, Becquemin MH, Marquette $\mathrm{CH}$, Rouby JJ. Lung tissue concentrations of nebulized amikacin during mechanical ventilation in piglets with healthy lungs. Am J Respir Crit Care Med 2002;165(2):171-175.

26. Elman M, Goldstein I, Marquette CH, Wallet F, Lenaour G, Rouby JJ, Experimental ICU Study Group. Influence of lung aeration on pulmonary concentrations of nebulized and intravenous amikacin in ventilated piglets with severe bronchopneumonia. Anesthesiology 2002;97(1):199-206.

27. Tonnellier M, Ferrari F, Goldstein I, Sartorius A, Marquette CH, Rouby JJ. Intravenous versus nebulized ceftazidime in ventilated piglets with and without experimental bronchopneumonia: comparative effects of helium and nitrogen. Anesthesiology 2005;102(5):995-1000.

28. Ferrari F, Lu Q, Girardi C, Petitjean O, Marquette CH, Wallet F, et al. Nebulized ceftazidime in experimental pneumonia caused by partially resistant Pseudomonas aeruginosa. Intensive Care Med 2009; 35(10): 1792-1800.

29. Lu Q, Girardi C, Zhang M, Bouhemad B, Louchahi K, Petitjean O, et al. Nebulized and intravenous colistin in experimental pneumonia caused by Pseudomonas aeruginosa. Intensive Care Med 2010;36(7): 1147-1155.

30. Bhavsar T, Liu M, Liu X, Cantor J. Aerosolized recombinant human lysozyme enhances the bactericidal effect of tobramycin in a hamster model of Pseudomonas aeruginosa-induced pneumonia. Exp Lung Res 2011;37(9):536-541.

31. Le Conte P, Potel G, Clémenti E, Legras A, Villers D, Bironneau E, et al. [Administration of tobramycin aerosols in patients with nosocomial pneumonia: a preliminary study]. Presse Med 2000;29(2): 76-78.
32. Hallal A, Cohn SM, Namias N, Habib F, Baracco G, Manning RJ, et al. Aerosolized tobramycin in the treatment of ventilator-associated pneumonia: a pilot study. Surg Infect 2007;8(1):73-82.

33. Ghannam DE, Rodriguez GH, Raad II, Safdar A. Inhaled aminoglycosides in cancer patients with ventilator-associated Gram-negative bacterial pneumonia: safety and feasibility in the era of escalating drug resistance. Eur J Clin Microbiol Infect Dis 2009;28(3):253-259.

34. Kofteridis DP, Alexopoulou C, Valachis A, Maraki S, Dimopoulou D, Georgopoulos D, Samonis G. Aerosolized plus intravenous colistin versus intravenous colistin alone for the treatment of ventilatorassociated pneumonia: a matched case-control study. Clin Infect Dis 2010;51(11):1238-1244.

35. Korbila IP, Michalopoulos A, Rafailidis PI, Nikita D, Samonis G, Falagas ME. Inhaled colistin as adjunctive therapy to intravenous colistin for the treatment of microbiologically documented ventilator-associated pneumonia: a comparative cohort study. Clin Microbiol Infect 2010;16(8):1230-1236.

36. Rattanaumpawan P, Lorsutthitham J, Ungprasert P, Angkasekwinai $\mathrm{N}$, Thamlikitkul V. Randomized controlled trial of nebulized colistimethate sodium as adjunctive therapy of ventilator-associated pneumonia caused by Gram-negative bacteria. J Antimicrob Chemother 2010;65(12):2645-2649.

37. Lu Q, Yang J, Liu Z, Gutierrez C, Aymard G, Rouby JJ Nebulized Antibiotics Study Group. Nebulized ceftazidime and amikacin in ventilator-associated pneumonia caused by Pseudomonas aeruginosa. Am J Respir Crit Care Med 2011;184(1):106-115.

38. Niederman MS, Chastre J, Corkery K, Fink JB, Luyt CE, García MS. BAY41-6551 achieves bactericidal tracheal aspirate amikacin concentrations in mechanically ventilated patients with Gram-negative pneumonia. Intensive Care Med 2012;38(2):263-271

39. Doshi NM, Cook CH, Mount KL, Stawicki SP, Frazee EN, Personett $\mathrm{HA}$, et al. Adjunctive aerosolized colistin for multi-drug resistant gram-negative pneumonia in the critically ill: a retrospective study. BMC Anesthesiol 2013;13(1):45.

40. Tumbarello M, De Pascale G, Trecarichi EM, De Martino S, Bello G, Maviglia R, et al. Effect of aerosolized colistin as adjunctive treatment on the outcomes of microbiologically documented ventilator-associated pneumonia caused by colistin-only susceptible gramnegative bacteria. Chest 2013;144(6):1768-1775.

41. Palmer LB, Smaldone GC. Reduction of bacterial resistance with inhaled antibiotics in the intensive care unit. Am J Respir Crit Care Med 2014;189(10):1225-1233.

42. Rose LM, Neale R. Development of the first inhaled antibiotic for the treatment of cystic fibrosis. Sci Transl Med 2010;2(63):63mr64. doi: 10.1126/scitranslmed.3001634.

43. Kleinstreuer C, Zhang Z, Li Z. Modeling airflow and particle transport/deposition in pulmonary airways. Respir Physiol Neurobiol 2008; 163(1):128-138.

44. Byron PR. Prediction of drug residence times in regions of the human respiratory tract following aerosol inhalation. J Pharm Sci 1986; 75(5):433-438.

45. Boe J, Dennis JH, O’Driscoll BR, Bauer TT, Carone M, Dautzenberg B, et al. European Respiratory Society Guidelines on the use of nebulizers: guidelines prepared by a European Respiratory Society Task Force on the use of nebulizers. Eur Respir J 2001;18(1):228-242.

46. Fink J, Ari A. Aerosol delivery to intubated patients: expert opinion on drug delivery 2013;10(8):1077-1093.

47. Hess DR, Dillman C, Kacmarek RM. In vitro evaluation of aerosol bronchodilator delivery during mechanical ventilation: pressure-control vs. volume control ventilation. Intensive Care Med 2003;29(7): 1145-1150.

48. Palmer LB, Smaldone GC, Chen JJ, Baram D, Duan T, Monteforte M, et al. Aerosolized antibiotics and ventilator-associated tracheobronchitis in the intensive care unit. Crit Care Med 2008;36(7):2008-2013. 
49. Nseir S. Aerosolized antibiotics for ventilator-associated tracheobronchitis: let's go with the flow! Crit Care Med 2008;36(7):2191-2192.

50. Myers TR. Year in review 2014: aerosol delivery devices. Respir Care 2015;60(8):1190-1196.

51. Fuller HD, Dolovich MB, Posmituck G, Pack WW, Newhouse MT. Pressurized aerosol versus jet aerosol delivery to mechanically ventilated patients: comparison of dose to the lungs. Am Rev Respir Dis 1990;141(2):440-444.

52. Dubus JC, Vecellio L, De Monte M, Fink JB, Grimbert D, Montharu $\mathrm{J}$, et al. Aerosol deposition in neonatal ventilation. Pediatr Res 2005; 58(1):10-14.

53. Steckel H, Eskandar F. Factors affecting aerosol performance during nebulization with jet and ultrasonic nebulizers. Eur J Pharm Sci 2003;19(5):443-455.

54. Sagalla RB, Smaldone GC. Capturing the efficiency of vibrating mesh nebulizers: minimizing upper airway deposition. J Aerosol Med Pulm Drug Deliv 2014;27(5):341-348.

55. Rouby JJ, Bouhemad B, Monsel A, Brisson H, Arbelot C, Lu Q, Nebulized Antibiotics Study Group. Aerosolized antibiotics for ventilator-associated pneumonia: lessons from experimental studies. Anesthesiology 2012;117(6):1364-1380.

56. Sartorius A, Lu Q, Vieira S, Tonnellier M, Lenaour G, Goldstein I, Rouby JJ. Mechanical ventilation and lung infection in the genesis of air-space enlargement. Crit Care 2007;11(1):R14.

57. Goldstein I, Bughalo MT, Marquette CH, Lenaour G, Lu Q, Rouby JJ, Experimental ICU Study Group. Mechanical ventilation-induced air-space enlargement during experimental pneumonia in piglets. Am J Respir Crit Care Med 2001;163(4):958-964.

58. Pelkonen AS, Nikander K, Turpeinen M. Jet nebulization of budesonide suspension into a neonatal ventilator circuit: synchronized versus continuous nebulizer flow. Pediatr Pulmonol 1997;24(4):282-286.

59. Miller DD, Amin MM, Palmer LB, Shah AR, Smaldone GC. Aerosol delivery and modern mechanical ventilation: in vitro/in vivo evaluation. Am J Respir Crit Care Med 2003;168(10):1205-1209.

60. O'Riordan TG, Palmer LB, Smaldone GC. Aerosol deposition in mechanically ventilated patients: optimizing nebulizer delivery. Am J Respir Crit Care Med 1994;149(1):214-219.
61. Goldstein I, Wallet F, Nicolas-Robin A, Ferrari F, Marquette CH, Rouby JJ. Lung deposition and efficiency of nebulized amikacin during Escherichia coli pneumonia in ventilated piglets. Am J Respir Crit Care Med 2002;166(10):1375-1381.

62. Valachis A, Samonis G, Kofteridis DP. The role of aerosolized colistin in the treatment of ventilator-associated pneumonia: a systematic review and metaanalysis. Crit Care Med 2015;43(3): 527-533.

63. Ramsey BW, Pepe MS, Quan JM, Otto KL, Montgomery AB, Williams-Warren $\mathrm{J}$, et al. Intermittent administration of inhaled tobramycin in patients with cystic fibrosis: Cystic Fibrosis Inhaled Tobramycin Study Group. N Engl J Med 1999;340(1):23-30.

64. McCoy KS, Quittner AL, Oermann CM, Gibson RL, Retsch-Bogart GZ, Montgomery AB. Inhaled aztreonam lysine for chronic airway Pseudomonas aeruginosa in cystic fibrosis. Am J Respir Crit Care Med 2008;178(9):921-928.

65. Imberti R, Cusato M, Villani P, Carnevale L, Iotti GA, Langer M, Regazzi M. Steady-state pharmacokinetics and BAL concentration of colistin in critically ill patients after IV colistin methanesulfonate administration. Chest 2010;138(6):1333-1339.

66. Harvey CJ, O’Doherty MJ, Page CJ, Thomas SH, Nunan TO, Treacher DF. Comparison of jet and ultrasonic nebulizer pulmonary aerosol deposition during mechanical ventilation. Eur Respir J 1997;10(4): 905-909.

67. Klompas M. Interobserver variability in ventilator-associated pneumonia surveillance. Am J Infect Control 2010;38(3):237-239.

68. Klompas M. Does this patient have ventilator-associated pneumonia? JAMA 2007;297(14):1583-1593.

69. Klompas M. The paradox of ventilator-associated pneumonia prevention measures. Crit Care 2009;13(5):315.

70. Tejerina E, Esteban A, Fernández-Segoviano P, Frutos-Vivar F, Aramburu J, Ballesteros D, Rodríguez-Barbero JM. Accuracy of clinical definitions of ventilator-associated pneumonia: comparison with autopsy findings. J Crit Care 2010;25(1):62-68.

71. Zampieri FG, Nassar AP Jr., Gusmao-Flores D, Taniguchi LU, Torres A, Ranzani OT. Nebulized antibiotics for ventilator-associated pneumonia: a systematic review and meta-analysis. Crit Care 2015; 19:150.

\section{Discussion}

Marini: One of the things needed to make an aerosolized antibiotic effective is that it reaches an airspace, and the airspaces of patients who have severe pneumonia have not been well characterized. In theory, the epithelial $\mathrm{pH}$, for example, could differ from blood $\mathrm{pH}$, and that could impede the antibiotic from either crossing into the bloodstream or being effective locally. Just a thought that I think we should entertain. Are they ineffective because of hostile environments at the point of action? Second, I think most people agree that an open airspace requires recruitment. PEEP has been looked at, of course, but positioning should be important as well-For example, whether the patient is bolt upright, supine, prone or in a lateral position. Particularly in a situation where you have a recruitable lobar pneumonia I would think that positioning would be an important factor. I'm wondering if either Michael [Klompas] or Lorenzo [Berra] can address that?

Berra: These are two interesting points. First of all, nebulized antibiotics are not just regular drugs or pills that you can administer at any point. When we decide to administer nebulized antibiotics, we need to take into consideration lots of information that we've learned from animal experiments over time. ${ }^{1}$ The critique that I have of a lot of these clinical trials is that the authors administer nebulized antibiotics as if these antibiotics were pills, but in reality this is not true. I totally agree that the alveolar space is a different environment, with a different $\mathrm{pH}$. We cannot extrapolate laboratory data and apply those to clinical conditions, such as the minimum inhibitory concentration. However this reasoning (and alveolar $\mathrm{pH}$ considerations) is true for both nebulizers and for intravenous antibiotics. The other thing I would like to emphasize is that despite the heterogeneity of the lungs, the concentration of antibiotics that can be delivered by inhalation are much higher than what can be given intravenously. Regarding body positioning and lung recruitment, none of the studies evaluated positioning or recruitment maneuvers, so that is a very 
interesting consideration because bronchial pneumonia and lobar pneumonia are not the same entity and should be prepared/treated differently before inhaled antibiotics. Studies back in the "60s and "70s showed failure of nebulized antibiotics while recent studies showed no superiority between intravenous and aerosolized antibiotics. My guess is that the antibiotics have stayed the same and we've improved a little bit the way in which we deliver antibiotics. Future studies needs to carefully take in consideration methods to deliver antibiotics, recruitment of lung parenchyma, and antibiotic distribution in the lungs. I would like to make one more observation: Panigada et $\mathrm{al}^{2}$ showed in sheep that areas of the lung that were atelectatic with purulent secretions had same bacterial count $(\mathrm{CFU} / \mathrm{mg})$ of areas of the lung well aerated and pink. Bacterial count was the same despite the different gross pathological appearance. While I agree that aeration means better delivery of antibiotics, this does not mean that bacteria are absent and aerosolized antibiotics are off target.

Marini: Can I add one more thing? When you aerosolize an antibiotic it goes through the endotracheal tube (ETT). That antibiotic might not all be lost just because it deposits on the artificial airway. And we don't know very much about the mucociliary escalator in an intubated sick patient with pneumonia on a ventilator. It's possible that antibiotic or any other inhaled particle becomes part of the liquid film that sinks toward the lung ... or at least closer to the parenchyma and closer to a point where the bronchial circulation can pick it up and effectively distribute the antibiotic. There are still a lot of things that we clinicians don't know. Perhaps the scientists do, but I for one, am uncertain.

Klompas: One wonders as well if aerosolized antibiotics may have some beneficial impact on the biofilm on the ETT. Maybe they inhibit further accumulation of biofilm. Maybe they eventually penetrate the biofilm, and what's the long-term impact of that? It's like the reverse of a coated ETT, you're putting the agent on the inside aspect of the biofilm rather than coating the surface of the ETT.

Kacmarek: Both of you discussed the way we should be ventilating patients during the delivery of aerosolized antibiotics. I could be wrong, but I would say we never ventilate patients that way. So, I think it's impossible to expect that we will see clinically the same results you see in the laboratory because I would assume that if we went through all the laboratory studies in detail and did ventilate as close to the ideal as possible we would create other problems.

\section{Klompas: In pigs.}

Kacmarek: Right. But in patients we're nowhere near that, we're really way off that approach based on the way we ventilate patients on a day-today basis.

Klompas: And is that approach actually safe? Is it feasible to have the patient adequately oxygenated for the period of aerosolization? We saw in a clinical study from Lu et $\mathrm{al}^{3}$ that some subjects' oxygenation suffered substantially during aerosolization.

Kacmarek: That's the issue of the expiratory filter, we put them in and we remove them but people make mistakes and forget at times. We've had issues with filters occluding, we haven't had a cardiac arrest but we have had elevated airway pressures and hemodynamic problems. It's just a difficult thing to do clinically, correctly. I don't think we do it correctly and I think there is a misconception on the part of physicians believing that things are done the way they're done in research protocols.
Klompas: The doctors think it's no big deal, 'Why not toss in some aerosols? It can only help; it won't hurt'. I think what we've learned is that to do aerosolized antibiotics correctly is not trivial and there is room for harm.

Kallet: To add to that, this is obviously a very specialized procedure and patient-ventilator synchrony is a huge thing. This might end up being in the future niche application, where someone with severe ARDS bacterial pneumonia where you probably are in the acute stage going to have them paralyzed or deeply sedated - prone them, recruit them. This might work in specific areas but the idea that it's like albuterol and you just put it in the nebulizer and everything will be fine, that's not going to work. But in limited applications this might actually be very good.

MacIntyre: I know Smaldone and others $^{4}$ have argued over the years that maybe pneumonia is not the right target here. Instead, tracheobronchitis (which might be the precursor to pneumonia) might be a better target for an aerosol. In concept, this might prevent the development of subsequent pneumonia. I know there are not much data, but I'd be interested whether our 2 experts think targeting tracheobronchitis is something worth pursuing further. In other words, purulent sputum but without a clear infiltrate.

Berra: That study ${ }^{4}$ was on tracheobronchitis specifically, and I think that makes perfect sense. However, I cannot underline enough the importance of well-conducted animal lab studies in this field. We just don't know enough. We can't start a multicenter trial. We are not there yet. There are too many knowledge gaps. While aeresolized antibiotics are promising we still have more to learn.

Mireles-Cabodevila: I guess my questions are 1) what about the bacteremic phase of the pneumonia? And 
how does inhaled antibiotics deal with that? 2) Based on what you are saying, to maximize delivery we have to paralyze these patients. That kind of doesn't make sense logistically. Is it worth the bang for the buck, in terms of workload, for my respiratory therapists to be setting up all the stuff to make it happen?

Klompas: The issue of bacteremic patients is an interesting one because there are 2 preferred strategies for using aerosolized antibiotics: an adjunct to intravenous or as a treatment unto itself. If you have intravenous antibiotics on board then presumably that will take care of your bacteremia or any distant loci of infection that might exist as well. If you're using the strategy of nebulization alone then you really have to worry if it can adequately take care of bacteremia. I know that we said there is some systemic absorption of these agents, but I think as Lorenzo pointed out they vary substantially by drug. Colistin in particular has very little systemic absorption and therefore is not appropriate. The one clinical study ${ }^{3}$ that looked at the strategy of nebulization alone vs intravenous alone excluded bacteremic subjects.

Hess: Back to the point Bob [Kacmarek] made. It might not be realistic to expect that with the current technology available to deliver aerosols during mechanical ventilation, that we can address everything you listed on your slide. Those of us who have to administer aerosolized medications would say, 'There's no way we're going to make those setting changes on the ventilator'. I think we will see new technology coming down the pipeline addressing aerosolized delivery of antibiotics. The issue, I think, will be whether we can afford it. Time will tell.
Berra: Again, this should be tested in animal studies. If paralysis is not used, we should learn precisely the dose and methods to deliver those antibiotics. We can adjust the dose according to patient scenarios and this is something we should carefully evaluate. In addition, some of these antibiotics have other benefits such as macrolides that might help mucociliary clearance and fragmentation of bacterial biofilm. These should also be evaluated.

Kacmarek: When, if ever, do you order aerosolized antibiotics?

Klompas: I never have.

Berra: We do use them. Bob, as you know, there are different approaches and beliefs among surgical teams. My take on this is that, while we do not have compelling data for the widespread use of aerosolized antibiotics, some patients might benefit from them. Aerosolized antibiotics might be helpful for patients infected with multidrug-resistant antibiotics, on high intravenous doses of antibiotics, or in renal failure - not as a monotherapy but as an adjunctive therapy.

Kacmarek: You don't order just aerosolized antibiotics; you order them in conjunction with systemic antibiotics.

Berra: This is correct, Bob.

Mireles-Cabodevila: And do you use that protocol to deliver it?

Hess: The answer would be no, right? We deliver the aerosol however the patient presents, we don't make all those adjustments.
Davies: So you don't feel the need to adjust the ventilator when delivering aerosolized antibiotics?

Berra: No, we do not. Usually patients who receive nebulized antibiotics are so sick they're often already paralyzed, or at least heavily sedated. In those patients the most important considerations before delivering aerosolized antibiotics are 1) drainage of secretions, 2) recruiting the lungs before using the drug, and 3) making sure that you have optimal clinical conditions for delivering the drugs (eg, avoiding bronchospasm by using albuterol before starting nebulization).

Davies: It'd be interesting to use it during a recruitment maneuver, or a series of them, and see what happens to the deposition.

\section{REFERENCES}

1. Rouby JJ, Bouhemad B, Monsel A, Brisson $\mathrm{H}$, Arbelot C, Lu Q; Nebulized Antibiotics Study Group. Aerosolized antibiotics for ventilator-associated pneumonia: lessons from experimental studies. Anesthesiology 2012;117(6):1364-1380.

2. Panigada M, Berra L, Greco G, Stylianou M, Kolobow T. Bacterial colonization of the respiratory tract following tracheal intubation-effect of gravity: an experimental study. Crit Care Med 2003;31(3):729-737.

3. Lu Q, Yang J, Liu Z, Gutierrez C, Aymard G, Rouby JJ. Nebulized ceftazidime and amikacin in ventilator-associated pneumonia caused by Pseudomonas aeruginosa. Am J Respir Crit Care Med 2011;184(1): 106-115.

4. Palmer LB, Smaldone GC, Chen JJ, Baram D, Duan T, Monteforte M, et al. http:// www.ncbi.nlm.nih.gov/pubmed/18552684 Aerosolized antibiotics and ventilatorassociated tracheobronchitis in the intensive care unit. Crit Care Med 2008;36(7): 2008-13.

This article is approved for Continuing Respiratory Care Education credit. For information and to obtain your CRCE

(free to AARC members) visit

www.rcjournal.com

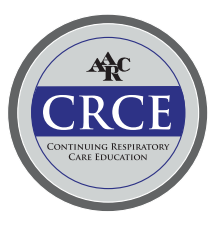

